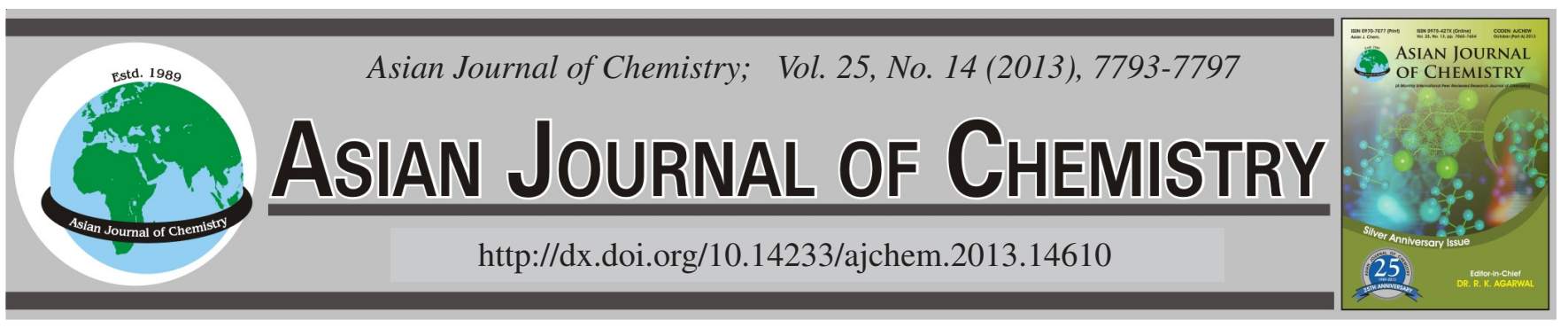

\title{
Swelling Equilibria and Procion Blue HERD Dye Adsorption Studies of 3,4-Epoxycyclohexylmethyl-3',4'-epoxycyclohexanecarboxylate-Based Polymeric Gels Prepared by Photoinitiated Cationic Polymerization
}

\author{
E. SAHIN ${ }^{1, *}$, M. Degirmeci ${ }^{2}$, F. SemdinOGLU ${ }^{2}$ and N. Genli ${ }^{2}$
}

${ }^{1}$ Department of Chemistry, Faculty of Science, Dokuz Eylul University, Buca 35160, Izmir, Turkey

${ }^{2}$ Department of Chemistry, Faculty of Science and Arts, University of Harran, Sanliurfa, Turkey

*Corresponding author: Fax: +90 2323014188; Tel: +90 2323019507; E-mail: elif.sahin@ deu.edu.tr

\begin{abstract}
In this study, superswelling behaviour of two different cross-linked polymer of 3,4-epoxycyclohexylmethyl-3',4'-epoxycyclohexanecarboxylate (EEC) monomer was investigated. The cross-linked polymer of EEC i.e., (PEEC) and EEC with cyclohexene end-functional polystyrene macromonomer (PEEC-co-PSt) were prepared by photoinitiated cationic polymerization using diphenyliodonium salt $\left(\mathrm{PhI}_{2}^{+}\right)$. The per cent swelling, equilibrium swelling, initial rate of swelling, swelling rate of constant and diffusion constant values were evaluated for PEEC and PEEC-co-PSt gel systems in dimethyl sulfoxide. PEEC and PEEC-co-PSt gels were swollen in the range 878-999 \% in DMSO. The adsorption of procion blue HERD dye onto PEEC and PEEC-co-PSt in DMSO solution was investigated. The equilibrium adsorption data on reactive dye on PEEC and PEEC-co-PSt were analyzed by Langmuir and Freundlich models. The maximum adsorption capacity $\left(\mathrm{q}_{\mathrm{m}}\right)$ has been found to be $556 \mathrm{mg} / \mathrm{g}$ for PEEC and $714 \mathrm{mg} / \mathrm{g}$ for PEEC-co-PSt gels.
\end{abstract}

Key Words: Swelling, Dye adsorption, Photoinitiated cationic homopolymerization, Copolymerization.

\section{INTRODUCTION}

Crosslinking polymer chains result in polymer networks called gels. Gels do not dissolve but swell/shrink (i.e., change their volume) in contact with liquid phases. This behaviour is responsible for many applications for example in drug delivery systems, molecular separation applications, biomedical devices such as artificial muscles, gel based sensors and display devices, adsorbents ${ }^{1-3}$. The swelling behaviours of crosslinking polymetric gel may cause its volume to change which is the macro exhibition of its conformational change of the macromolecular chain. Therefore, research on the swelling behaviours of crosslinking polymeric gels may reveal the interaction of microscopic molecules, conformational relationship of the macromolecular chain and flowing process of liquid infiltration and exudation ${ }^{4,5}$, which is of important value to deeply understand the mechanism of the gel.

Crosslinking polymer can be synthesized via various methods including anionic, cationic, radical polymerizations and chemical modifications of polymer ends ${ }^{6}$. In recent years, a bulk of research has been focused on the characterization and swelling behaviour of gels prepared by simultaneous free radical copolymerization and crosslinking in the presence of an initiator and a crosslinking agent ${ }^{7-10}$. Saraydin et al. have studied radiation induced acrylamide based hydogels to analyze the adsorption of proteins, pharmaceuticals, cationic dyes and heavy metal ions ${ }^{11}$. Unlike the others, we used photoinitiated cationic (co)polymerization in this study ${ }^{12}$.

Synthetic dyes have been extensively used in many industries such as textile, leather tanning, paper production, food technology, photoelectrochemical cells, hair colourings, biomaterial in medicine, pharmaceutical and veterinary industries etc. ${ }^{13-15}$. A number of textile dyes, known as reactive dyes, have been used to purify proteins. Selection of the supporting matrix or gel is the first important consideration in dye-affinity systems. There are several methods for immobilization of dye molecules onto the supporting matrix or gel. The adsorption should carefully be optimized to design a successful separation.

The aim of this study is to investigate the swelling properties and adsorption characteristics of gels. Dynamic swelling studies are important for swelling characterization of polymeric gel systems. These swelling properties are of particular importance in textile industry, biomaterial in medicine, pharmaceutical and veterinary industries.

\section{EXPERIMENTAL}

Styrene (Fluka) was distilled over calcium hydride and stored in a refrigerator under nitrogen before use. The 
compounds 3-cyclohexene-1-methanol (Aldrich), 2-bromopropanoyl bromide (Aldrich), 3-chloroperoxybenzoic acid (Aldrich) and sodium bicarbonate (Merck) were used as received. The compound 3,4-epoxycyclohexylmethyl-3',4'epoxycyclohexanecarboxylate (EEC) was commercially obtained from Ciba Specialty Chemicals and used as received without further purification. Dichloromethane (Lab-scan), dimethyl sulfoxide (Merck), pyridine (Lab-Scan), diphenyliodonium hexafluorophosphate $\left(\mathrm{Ph}_{2} \mathrm{I}^{+} \mathrm{PF}_{6}{ }^{-}\right)$(Fluka), $\mathrm{CuBr}$ (Aldrich), 2,2'-bipyridine (Merck) and all other solvents and chemicals were used as received. Swelling work was made at room temperature and room atmosphere with DMSO. In the adsorption part of this study, procion blue HERD (Aldrich) was used.

Polymerization procedure: Cyclohexene oxide endfunctional macromonomer of polystyrene (CHO-PSt) was synthesized by atom transfer radical polymerization (ATRP) method. In Scheme-I (Table-1), syntheses of CHO-PSt as well as the characteristic of the investigated polymer are given. The details of polymerization conditions and characterization processes were currently available from a previous article ${ }^{16}$.

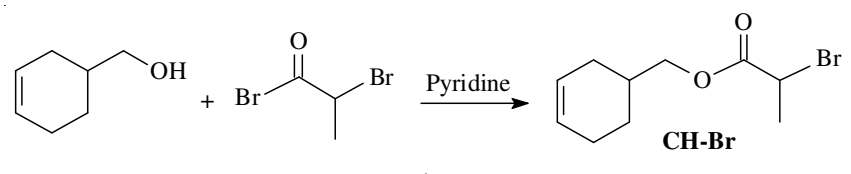

1

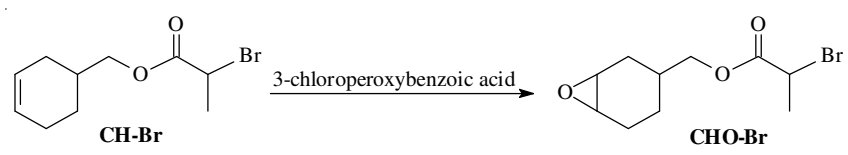
2

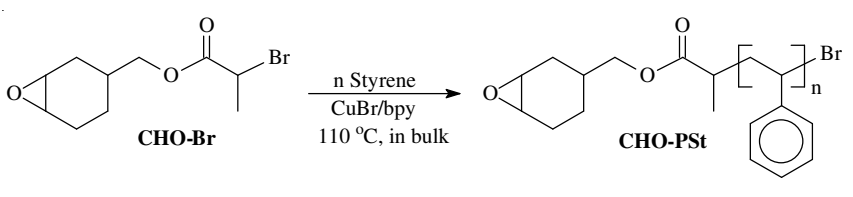
3

Scheme-I: Preparation of cyclohexene oxide end-functional macromonomer of polystyrene (CHO-PSt)

TABLE-1

SYNTHESIS OF CHO END-FUNCTIONAL MACROMONOMERS OF PSt BY ATRP ${ }^{\mathrm{a}}$ USING CHO-Br AS INITIATOR

\begin{tabular}{ccccccc}
$\begin{array}{c}{[\mathrm{I}] \times 10^{-2}} \\
(\mathrm{~mol} / \mathrm{l})\end{array}$ & $\begin{array}{c}\text { Time } \\
(\mathrm{min})\end{array}$ & $\begin{array}{c}\text { Conversion } \\
(\%)\end{array}$ & $\mathrm{M}_{\mathrm{n} \text { theo }}$ & $\begin{array}{c}\mathrm{M}_{\mathrm{n}} \\
\mathrm{b}\end{array}$ & $\mathrm{M}_{\mathrm{w}} / \mathrm{M}_{\mathrm{n}}$ & $\begin{array}{c}\mathrm{M}_{\mathrm{nH}} \\
\mathrm{NMR}\end{array}$ \\
\hline 28.9 & 90 & 39 & 1490 & 1590 & 1.27 & 1920
\end{tabular}

${ }^{\text {aTemperature }} 110{ }^{\circ} \mathrm{C},[\mathrm{St}]_{0}=8.75 \mathrm{~mol} / \mathrm{L}$ (in bulk), $[\mathrm{I}]:[\mathrm{CuBr}]:[\mathrm{Bpy}]=$ $1: 1: 3,{ }^{b}$ Determined by GPC according to PSt standards.

Photoinitiated cationic polymerization method was applied to prepare cross-linked polymers. Photopolymerizations were carried out in $\mathrm{CH}_{2} \mathrm{Cl}_{2}$ solution. In the preparation of PEEC the monomer 3,4-epoxycyclohexylmethyl-3',4'-epoxycyclohexanecarboxylate $(\mathrm{EEC})\left(5.95 \times 10^{-3} \mathrm{~mol} / \mathrm{L}\right)$ and the cationic photoinitiator diphenyliodonium hexafluorophosphate $\left(\mathrm{Ph}_{2} \mathrm{I}^{+} \mathrm{PF}_{6}^{-}\right)\left(5 \times 10^{-3} \mathrm{~mol} / \mathrm{L}\right)$ were placed in a quartz tube. The cationic photoinitiator $\mathrm{Ph}_{2} \mathrm{I}^{+} \mathrm{PF}_{6}^{-}\left(5 \times 10^{-3} \mathrm{~mol} / \mathrm{L}\right)$ and the macromonomer CHO-PSt $(100 \mathrm{~g} / \mathrm{L})$ were placed in another quartz tube to prepare PEEC-co-PSt the monomer (EEC) $\left(5.95 \times 10^{-3} \mathrm{~mol} / \mathrm{L}\right)$. The tubes were degassed with nitrogen prior to irradiation by a merry-go-round type photoreactor equipped with 16 lamps emitting light nominally at $\lambda=300$ $\mathrm{nm}$ and a cooling system. At the end of the reaction, crosslinked polymers were filtered, dried and weighed.

Experiments of swelling and diffusion: The swelling behaviours of dried gels were carried out by immersion in DMSO at $25^{\circ} \mathrm{C}$ in a water bath to measure the parameters of diffusion and swelling. Swollen gels removed from the DMSO at regular intervals were dried superficially with filter paper, weighted and placed in the same bath again. Swollen gels weighted by an electronic balance (Sertorious CP 224S). The measurements were continued until a constant weight was reached for each sample.

Adsorption studies: The equilibrium adsorption isotherm was determined using batch studies. Samples, consisting of a portion $(0.1 \mathrm{~g})$ of the adsorbent material gel and various initial dye concentrations $20-200 \mathrm{mg} / \mathrm{L}$, were poured into the conical reaction flask. The time required to reach equilibrium as determined in equilibrium studies was $24 \mathrm{~h}$. The effect of the adsorption isotherm was determined by examining the series of isotherms at $30^{\circ} \mathrm{C}$. The sample, $0.1 \mathrm{~g}$ of dry gel, was transferred into $50 \mathrm{~mL}$ of the synthetic DMSO solutions of the dye and allowed to equilibrate for $24 \mathrm{~h}$ at $30^{\circ} \mathrm{C}$. The influences of PSt content in the superswelling gels were investigated for adsorption of dye onto PEEC and PEEC-co-PSt gels. Spectrophotometric method was applied to dye solutions. Spectrophotometric measurements were taken using a Shimadzu UV 1601 model UV-visible spectrophotometer at ambient temperature. The absorbances of these solutions were read at 650 $\mathrm{nm}$. DMSO was chosen as the reference. The equilibrium concentrations of the reactive dye solutions were determined by means of precalibrated scales.

\section{RESULTS AND DISCUSSION}

Preparation of PEEC and PEEC-co-PSt cross-linked polymers: Photoinitiated cationic polymerization of 3,4epoxycyclohexylmethyl-3',4'-epoxy- cyclohexanecarboxylate (EEC) with and without cyclohexene oxide end-functional macromonomer of polystyrene (CHO-PSt) was performed in $\mathrm{CH}_{2} \mathrm{Cl}_{2}$ at room temperature using diphenyliodonium salt $\left(\mathrm{PhI}_{2}^{+}\right)$as a cationic photoinitiator. EEC can ultimately form cross-linked networks with and without CHO-PSt upon irradiation in the presence of $\mathrm{PhI}_{2}{ }^{+}$due to the two epoxy groups present in the structure. The overall reactions for synthesis of PEEC and PEEC-co-PSt are depicted in Scheme-II.

Swelling measurements in DMSO: Equilibrium swelling experiments were carried out to investigate the swelling properties of the materials which were prepared using the various preparation methods. Dry gels were weighed and then immersed in DMSO at $30^{\circ} \mathrm{C}$. Swollen gels were removed from DMSO at predetermined intervals, blotted dry and weighed in air. The percentage swelling (or mass swelling) is the most important parameter about swelling studies. The percentage swelling ( $\%$ ) was calculated using the following equation ${ }^{17}$ :

$$
\mathrm{S}(\%)=\frac{\left(\mathrm{W}_{0}-\mathrm{W}_{\mathrm{t}}\right)}{\mathrm{W}_{0}} \times 100
$$




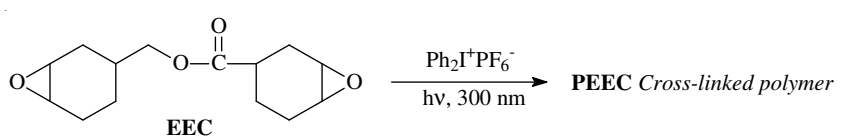

4

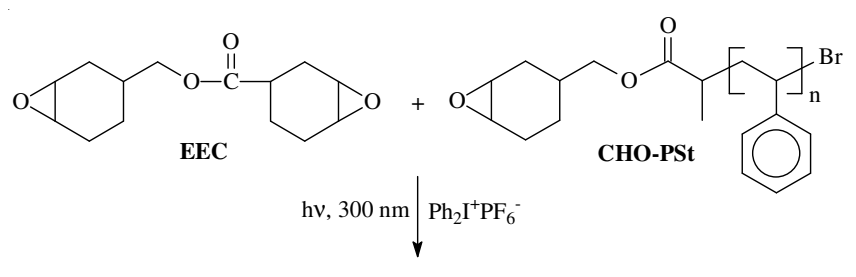

PEEC-co-PSt Cross-linked polymer

5

Scheme-II: Preparation of PEEC and PEEC-co-PSt cross-linked polymers

where $\mathrm{W}_{\mathrm{t}}$ is the mass of the swollen gel at time $\mathrm{t}$ and $\mathrm{W}_{0}$ is the mass of the dry gel at time 0 .

The DMSO intake of initially dried gels was observed for a prolonged duration of time. Swelling isotherms of PEEC and PEEC-co-PSt gel are plotted as shown in Fig. 1. It can be seen that the swelling $(\mathrm{S}) \%$ increases with time until a certain point, when it becomes constant. This value of S $\%$ may be named "equilibrium" swelling $\left(\mathrm{S}_{\mathrm{eq}} \%\right)$. The values of $\mathrm{S}_{\mathrm{eq}} \%$ of PEEC and PEEC-co-PSt gel are 878 and $999 \%$ (Table-2). The effects of crosslinker are important in preparing of PEECco-PSt. The reason behind this behaviour may be the molecular structure of crosslinkers. That is the reason PSt is behaving as crosslinkers.

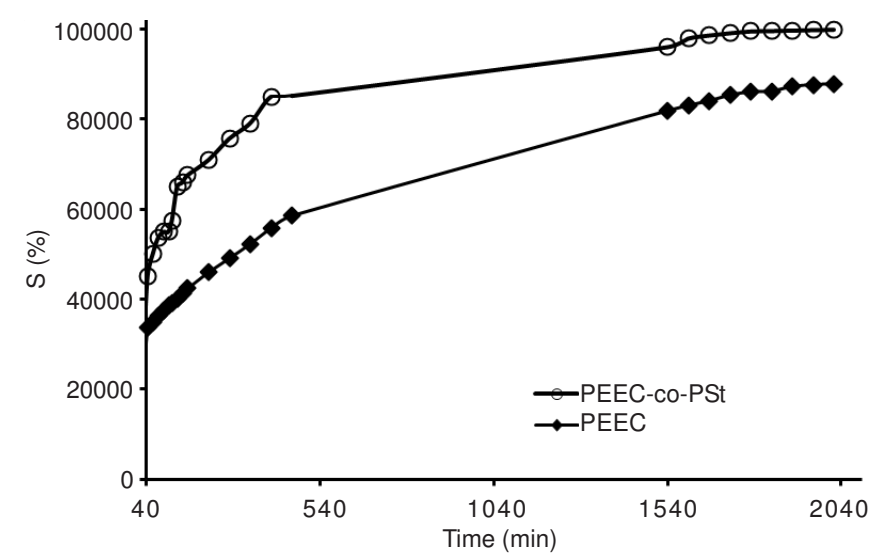

Fig. 1. Swelling isotherms of PEEC and PEEC-co-PSt gels

\begin{tabular}{|c|c|c|c|}
\hline \multicolumn{4}{|c|}{$\begin{array}{c}\text { TABLE-2 } \\
\text { SWELLING KINETICS PARAMETERS OF PEEC } \\
\text { AND PEEC-co-PSt GEL SYSTEMS IN DMSO }\end{array}$} \\
\hline & $\begin{array}{l}\text { Initial swelling } \\
\text { rate, } \mathrm{r}(\mathrm{dS} / \mathrm{dt})_{0} \\
\mathrm{~g}_{\mathrm{DMSO} / \mathrm{g}_{\mathrm{gel}}}(\mathrm{min})\end{array}$ & $\begin{array}{l}\text { Swelling rate } \\
\text { constant, } \mathrm{k}_{2 . \mathrm{S}} \times \\
10^{5} ; \underset{\text { ggel } / \mathrm{g}_{\mathrm{DMSO}}}{(\mathrm{min})}\end{array}$ & $\begin{array}{c}\text { Theoretical } \\
\text { equilibrium } \\
\text { swelling, } \mathrm{S}_{\mathrm{eq}} \% \\
\text { max; } \mathrm{g}_{\mathrm{DMSO} / \mathrm{g}_{\mathrm{gel}}}\end{array}$ \\
\hline PEEC & 0.10 & 1.18 & 909 \\
\hline PEEC-co-PSt & 0.08 & 1.30 & 1000 \\
\hline
\end{tabular}

Swelling kinetics: In order to examine the controlling mechanism of the swelling processes, several kinetic models are used to test experimental data. The large number and array of different chemical groups on the PEEC and PEEC-co-PSt gel chains imply that there are many types of polymer-solvent interactions. It is probable that any kinetics is likely to be global. From a system design viewpoint, a lumped analysis of swelling rates is thus sufficient to the practical operation. A simple kinetic analysis is a second order equation in the form of

$$
\frac{\mathrm{dS}}{\mathrm{dt}}=\mathrm{k}_{2, \mathrm{~S}}\left(\mathrm{~S}_{\mathrm{eq}}-\mathrm{S}\right)
$$

where $\mathrm{k}_{2, \mathrm{~S}}$ is the rate constant of swelling and $\mathrm{S}_{\mathrm{eq}}\left(\right.$ or $\mathrm{S}_{\mathrm{eq}} \%$ ) denotes the swelling per cent at equilibrium. After definite integration by applying the initial conditions $S=0$ at $t=0$ and $\mathrm{S}=\mathrm{S}$ at $\mathrm{t}=\mathrm{t}$, eqn. 2 becomes

$$
\frac{\mathrm{t}}{\mathrm{S}}=\mathrm{A}+\mathrm{Bt}
$$

where $A$ is reciprocal of initial swelling rate $r_{0}$ or $1 / \mathrm{k}_{2, \mathrm{~S}} \mathrm{~S}_{\text {eq }}^{2}$ and $\mathrm{B}=1 / \mathrm{S}_{\mathrm{eq}}$ is inverse of the degree of swelling at equilibrium form $^{18}$. To test the kinetics model, $t / S$ versus $t$ graphs are plotted and representative graphs are illustrated in Fig. 2. The calculated kinetic parameters are tabulated in Table-2.

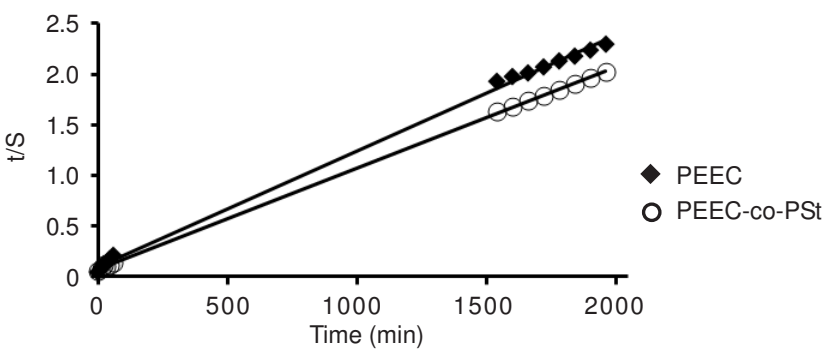

Fig. 2. Swelling kinetics curves of PEEC and PEEC-co-PSt gel in DMSO solutions

As can be seen from Table-2, the swelling rate constant is decreased in PEEC-co-PSt copolymer. This is plausible for the network to enhance with the extent of PSt polymeric groups in structure.

Diffusion: The swelling curves of PEEC and PEEC-coPSt gels in DMSO were used to calculate a certain diffusion characteristics. The following equation was used to determine the nature of diffusion of DMSO into gels ${ }^{19,20}$.

$$
\mathrm{F}=\mathrm{kt}^{\mathrm{n}}
$$

where F denotes the amount of DMSO diffused into the gel at time, $\mathrm{t}$ is infinite time (at equilibrium), $\mathrm{k}$ is a constant related to the structure of the network and the exponent ' $n$ ' is a numerical value to determine the type of diffusion. For a cylindrical shapes, $\mathrm{n} \leq 0.50$ corresponds to Fickian diffusion, whereas $0.50<\mathrm{n}<1.00$ to indicate diffusion is non-Fickian. Eqn. 4 was applied to various stages of swelling. Plots of $\ln \mathrm{F}$ against ln t yielded straight lines from which the exponent's $\mathrm{n}$ and $\mathrm{k}$ were calculated from the slope and intercept of the lines given in Table-3 both for PEEC and PEEC-co-PSt gel systems in DMSO. It can be clearly seen from the table that the values of the diffusion exponent, falling in the range from 0.27 to 0.29 are lower than 0.50 . Hence, the diffusion of DMSO into PEEC and PEEC-co-PSt gels were assumed to be Fickian in character. Table-4 also demonstrates that diffusion of DMSO is higher at PEEC-co-PSt because of the PSt higher cross-linking density.

Equilibrium isotherms for reactive dye adsorption on PEEC and PEEC-co-PSt gels: Adsorption isotherm data on 


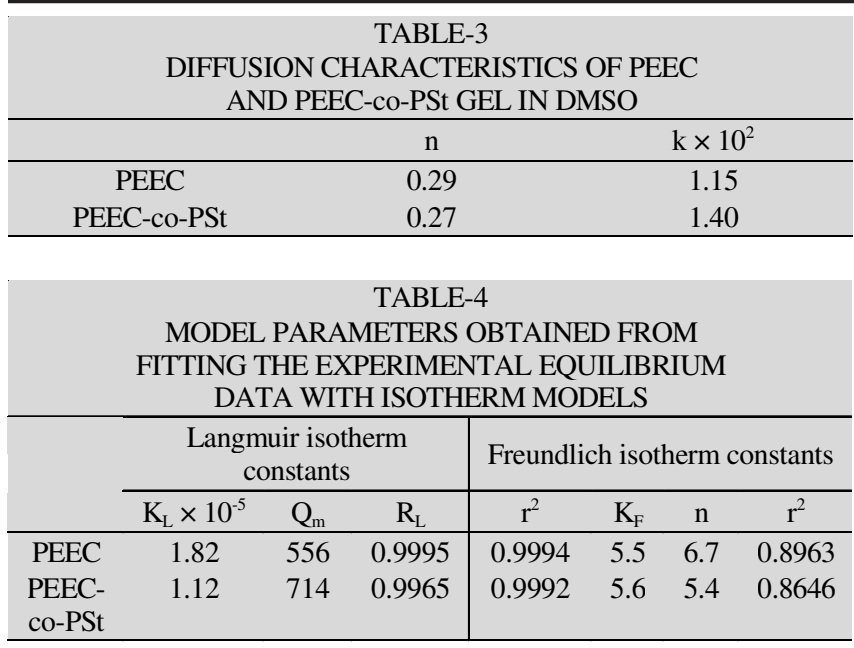

the reactive dyes are illustrated in Fig. 3. The shape of the isotherms indicates L2-behaviour according to Giles and Smith classification $^{21}$. In L2-type isotherms, adsorption of solute on the adsorbent proceeds until a monolayer is established, with the formation of more than one layer not being possible. The shape of isotherm presented in Fig. 3 is indicative of high affinity between the sorbent surface and the reactive dye molecules. The adsorbent effectively removes the dye at low initial concentrations; at higher concentrations the isotherms reach a maximum capacity as indicated by the plateau of the data. Most reported adsorption isotherms of reactive dyes were of L2-type isotherm ${ }^{22,23}$.

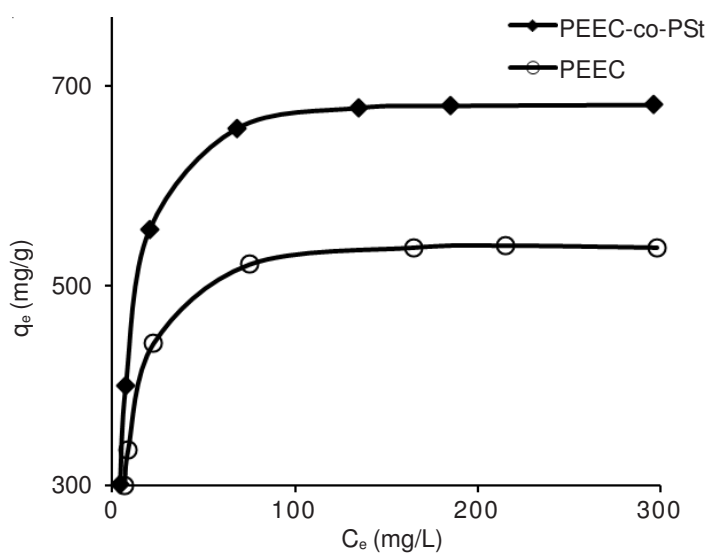

Fig. 3. Adsorption isotherms of reactive dyes. Mass of gel: $0.025 \mathrm{~g}$; volume of solution: $25 \mathrm{~cm}^{3}$; temperature: $25^{\circ} \mathrm{C}$. Points: experimental data; lines: Langmuir model

Accordingly, the anionic reactive dye molecules favourably adsorb on the gel surface with low competition from solvent molecules, with this adsorption process continuing until the surface concentration reaches a maximum value. In addition, multilayers of adsorbate failed to form due to the electrostatic repulsion between adsorbed molecules and those in solution.

Langmuir and Freundlich equilibrium isotherm models: The experimental data were applied to the Langmuir, Freundlich isotherm model. The Langmuir model assumes chemisorption on a set of well defined localized sorption sites, having the same sorption energies independent of surface coverage and no interaction between adsorbed molecules. Langmuir isotherm assumes monolayer coverage of sorbate onto sorbent. Freundlich isotherm allows an expression encompassing the surface heterogeneity and the exponential distribution of active sites and their energies. This isotherm does not estimate any saturation of the sorbent surface; thus infinite surface coverage is predicted, indicating physisorption on the surface.

The correlation of the experimental adsorption data with a number of adsorption models was undertaken to gain an understanding of the adsorption behaviour and the heterogeneity of the adsorbent surface. The Langmuir equation can be represented as follows ${ }^{24}$ :

$$
q_{e}=\frac{q_{m} \cdot K_{L} \cdot C_{e}}{1+K_{L} \cdot C_{e}}
$$

where $C_{e}(\mathrm{mg} / \mathrm{L})$ is the equilibrium concentration of dye in solution; $\mathrm{q}_{\mathrm{e}}(\mathrm{mg} / \mathrm{g})$ is the surface concentration of dye at equilibrium; $\mathrm{q}_{\mathrm{m}}(\mathrm{mg} / \mathrm{g})$ is the amount of dye adsorbed at complete monolayer coverage; $\mathrm{K}_{\mathrm{L}}(\mathrm{L} / \mathrm{mg})$ is a constant that relates to the energy of adsorption. The linearized Langmuir equation is represented as follows:

$$
\frac{1}{\mathrm{qe}}=\frac{1}{\mathrm{qm}}+\frac{1}{\mathrm{~K}_{\mathrm{L}} \cdot \mathrm{q}_{\mathrm{m}} \cdot \mathrm{C}_{\mathrm{e}}}
$$

The values of $\mathrm{q}_{\mathrm{m}}$ and $\mathrm{K}_{\mathrm{L}}$ were calculated from the slope and intercept of the straight lines of the plot $1 / \mathrm{C}_{\mathrm{e}}$ versus $1 / \mathrm{q}_{\mathrm{e}}$. The essential characteristic of the Langmuir isotherm can be expressed in terms of a dimensionless equilibrium parameter, such as the separation factor (or) equilibrium factor $\left(\mathrm{R}_{\mathrm{L}}\right)$ used in the following equation:

$$
\mathrm{R}_{\mathrm{L}}=\frac{1}{1+\mathrm{K}_{\mathrm{L}} \cdot \mathrm{C}_{\mathrm{e}}}
$$

This parameter indicates that isotherm will shape according to the following adsorption characteristics: $R_{L}>1$ unfavourable; $\mathrm{R}_{\mathrm{L}}=1$ corresponds to linear; $0<\mathrm{R}_{\mathrm{L}}<1$ is favourable and $\mathrm{R}_{\mathrm{L}}=0$ is irreversible as given in Table-4. It can be seen that the adsorption of Procion Blue HERD onto PEEC and PEEC-co-PSt gels will be favourable. The correlation of the dye adsorption data with the Langmuir isotherm model was high, with $\mathrm{r}^{2}$ values of 0.9994 and 0.9992 for PEEC and PEEC-co-PSt gel, respectively.

The Freundlich model can take the following form:

$$
\mathrm{q}_{\mathrm{e}}=\mathrm{K}_{\mathrm{F}} \cdot \mathrm{C}_{\mathrm{e}}{ }^{1 / \mathrm{n}}
$$

where $K_{F}\left[\mathrm{mg} / \mathrm{g}(\mathrm{L} / \mathrm{mg} /)^{\mathrm{n}}\right]$ represents the adsorption capacity when dye equilibrium concentration $\left(C_{e}\right)$ equals 1 with $n$ being the degree of dependence of adsorption on equilibrium concentration. The model parameters (as obtained from linearregression analysis) and correlation coefficients $\left(\mathrm{r}^{2}\right)$ are presented in Table-4.

$$
\ln \mathrm{q}_{\mathrm{e}}=\frac{\ln \mathrm{K}_{\mathrm{F}}}{(1 / \mathrm{n}) \ln \mathrm{C}_{\mathrm{e}}}
$$

Various constants associated with the isotherm are the intercept, which is roughly an indicator of sorption capacity $\left(\mathrm{K}_{\mathrm{F}}\right)$ and the slope $(1 / \mathrm{n})$, being the sorption intensity. The values are given in Table-4. The Freundlich isotherm has been illustrated to be a special case of heterogeneous surface energies but it can be easily extended to this case. It has been stated ${ }^{25,26}$ that the magnitude of the exponent $1 / n$ gives an indication of 
the favorability and capacity of the adsorbent/adsorbate system. Values where $\mathrm{n}>1$ represent favorable adsorption conditions. In most cases the exponent falling in the interval $1<\mathrm{n}<10$ shows beneficial adsorption.

The values for $\mathrm{q}_{\mathrm{m}}, \mathrm{K}_{\mathrm{L}}, \mathrm{K}_{\mathrm{F}}$ and $\mathrm{n}$ are summarized in Table4. The analyses of correlation coefficients showed that Langmuir isotherm provided the best fit of experimental adsorption data $\left(R_{L}>0.99\right)$. The fact that the Langmuir isotherm fits the experimental data very well may be due to the homogeneous distribution of active sites onto the PEEC and PEEC-co-PSt, since the Langmuir equation assumes that the surface is homogenous. Thus, Langmuir model was chosen to interpret procion blue HERD dye adsorption by PEEC and PEEC-co-PSt.

The maximum adsorption capacity observed for PEECco-PSt $(714 \mathrm{mg} / \mathrm{g})$ was almost 1.3 times greater than that of PEEC (556 mg/g). Maximum adsorption capacities of PEEC increased with content of polystyrene.

The parameter $\mathrm{K}_{\mathrm{F}}$ is a Freundlich constant that indicates the adsorption capacity of an adsorbent and is a constant which shows the strength of the relationship between adsorbate and adsorbent ${ }^{26}$. The value $\mathrm{K}_{\mathrm{F}}$ of PEEC and PEEC-co-PSt for procion blue HERD dye is $c a .5 .5(\mathrm{~L} / \mathrm{g})$. It is generally accepted that the values of $n$ in the range of 1-10 represent good adsorption. In the present work, the exponent $\mathrm{n}$ was in the range from 1-10, indicating favorable adsorption. The results given in Table-4 show that the adsorption of procion blue HERD dye onto PEEC-co-PSt is favorable.

PEEC and PEEC-co-PSt gels are new materials as an adsorbent. It is important to point out that the results obtained from adsorption studies, based on a number of experiments, have shown that each polymeric sample and derivatives have their own adsorption features, which relate to crosslinking degree.

\section{Conclusion}

In this study, PEEC and PEEC-co-PSt cross-linked polymers were prepared via photoinitiated cationic polymerization. Photoinitiation of cationic polymerizations can be efficiently achieved using EEC with and without $\mathrm{CHO}-\mathrm{PSt}$ co-monomer by aid of the iodonium salt at $300 \mathrm{~nm}$. Gels were prepared in DMSO and swollen to equilibrium in DMSO. Gel systems swelled in the range 878-999\%. Equilibrium swelling data were used to determine swelling parameters such as swelling exponent, swelling coefficients and diffusional behaviour of DMSO of the gel systems. Gels were of the type a Fickian diffusion character. It was seen that swelling of PEEC-co-PSt gel increased with contents of polystyrene. The second part of this study has shown that PEEC and PEEC-co-PSt adsorb the reactive dye, being the procion blue HERD. Langmuir model suitably fitted in the present system shows the formation of a monolayer covering of the adsorbate at the outer space of the adsorbent. The Freundlich model was used to analyze the isotherm. The monolayer adsorption capacity was determined to be reasonably high at PEEC-co-PSt for adsorption of Procion Blue HERD. The values of dimensionless equilibrium parameters like the separation factor (RL) indicate the favorability of the process described in the present study. We demonstrate that the Langmuir and Freundlich models can provide adequate representations of the data used in this study to describe dye sorption onto PEEC and PEEC-co-PSt gels at equilibrium, rendering a better fit. Hence the data reported here are quite useful to produce some substances to be used in pharmaceutical, environmental and biomedical applications, or in the applications of immobilized biologically active molecules. The results also showed that the PEEC and PEEC-co-PSt gels being useful as adsorbent for the DMSO pollutants such as reactive dyes, an important problem encountered in the biomedical and pharmaceutical industries.

\section{ACKNOWLEDGEMENTS}

The authors thank Harran University, the Scientific Research Council (HÜBAK) for financial support.

\section{REFERENCES}

1. A.E. Ivanov, V.V. Saburov and V.P. Zubov, Adv. Polym. Sci., 104, 135 (1992).

2. D. Saraydin, Y. Isikver, E. Karadag, N. Sahiner and O. Güven, Nucl. Instrum. Methods Phys. Res. B, 187, 340 (2002).

3. Y.-Q. Zhou, J. Huang, P.-F. Han and X.-P. Lv, Asian J. Chem., 24, 2007 (2012).

4. Z.Q. Gu, J.M. Xiao and X.H. Zhang, J. Biomed. Eng., 16, 13 (1999).

5. M.Z. Liu, R.S. Cheng and R.Y. Qian, Acta Polym. Sin., 2, 234 (1996).

6. H.N. Oztop, A.Y. Oztop, Y. Isikver and D. Saraydin, Process Biochem., 37, 651 (2002).

7. D. Saraydin, E. Karadag, Y. Çaldiran and O. Güven, Radiat. Phys. Chem., 60, 202 (2001).

8. D. Saraydin, E. Karadag and O. Güven, Sep. Sci. Technol., 31, 423 (1996).

9. E. Karadag, D. Saraydin and O. Güven, J. Appl. Polym. Sci., 61, 2367 (1996).

10. E. Karadag, D. Saraydin and O. Güven, Polym. Bull., 36, 745 (1996).

11. D. Saraydin, E. Karadag and O. Güven, Sep. Sci. Technol., 30, 3287 (1995).

12. Y. Yagci, O. Nuyken, V. Graubner and J.I. Kroschwitz, In Encylopedia of Polymer Science, New York: Wiley, edn. 3 (2005).

13. E. Forgacs, T. Cserhati and G. Oros, Environ. Int., 30, 953 (2004).

14. S. Papic, N. Koprivanac, A.L. Bozic and A. Metes, Dyes Pigments, 62, 293 (2004)

15. T.H. Kim, C.H. Park, E.B. Shin and S.Y. Kim, Desalination, 161, 49 (2004).

16. M. Degirmenci, O. Izgin, A. Acikses and N. Genli, React. Funct. Polym., 70, 28 (2010).

17. A.R. Khare and N.A. Peppas, Biomaterials, 16, 559 (1995).

18. C. Peniche, M.A. Cohen, B. Vazquez and J.S. Roman, Polymer, 38, 5977 (1997).

19. N.A. Peppas and N.M. Franson, J. Polym. Sci. B: Polym. Phys., 21, 983 (1983).

20. M.T. am Ende and N.A. Peppas, J. Control. Rel., 48, 47 (1997).

21. C. Giles, D. Smith and A. Huitson, J. Colloid Interf. Sci., 47, 755 (1974).

22. S. Wang, Y. Boyjoo, A. Choueib and H. Zhu, Water Res., 39, 129 (2005).

23. P.C.C. Faria, J.J.M. Orfao and M. Pereira, Water Res., 38, 2043 (2004).

24. R. Moreira, N. Kuhnen, M. Peruch, Latin Am. Appl. Res., 28, 37 (1998).

25. D. Chatzopoulos, A. Varma and R. Irvine, AIChE J., 39, 2027 (1993).

26. Y.S. Ho and G. McKay, J. Environ. Sci. Health, A34, 1179 (1999). 